Working Paper n. 01 - 2013

\title{
FATIGUE AND TEAM PERFORMANCE IN SOCCER: EVIDENCE FROM THE FIFA WORLD CUP AND THE UEFA EUROPEAN CHAMPIONSHIP
}

\author{
Vincenzo Scoppa \\ Dipartimento di Scienze Economiche, \\ Statistiche e Finanziarie \\ Università della Calabria \\ Ponte Pietro Bucci, Cubo 1/C \\ Tel.: +390984 492464 \\ Fax: +390984492421 \\ e-mail: v.scoppa@unical.it
}

\section{Gennaio 2013}

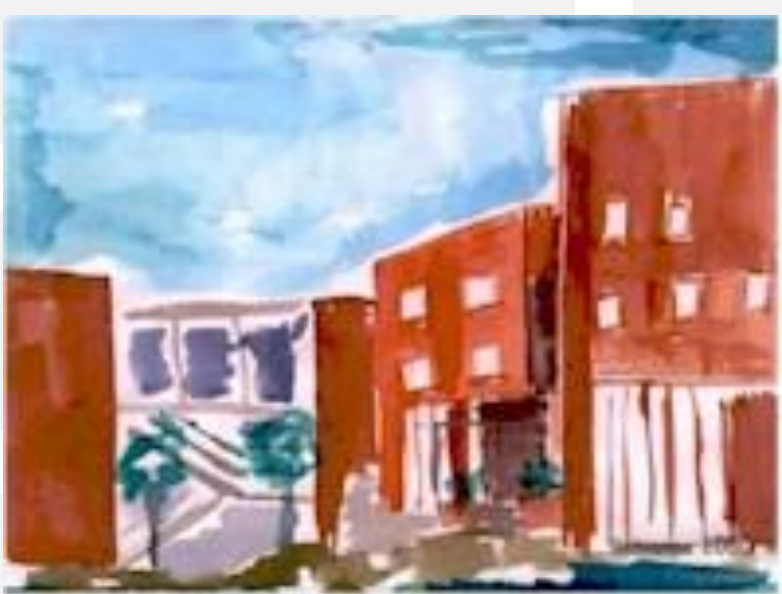




\title{
Fatigue and Team Performance in Soccer: Evidence from the FIFA World Cup and the UEFA European Championship
}

\author{
Vincenzo Scoppa*
}

This version: $14 / 01 / 2013$

\begin{abstract}
We investigate the role of fatigue in soccer (football). Although this issue is important for the "productivity" of players and the optimal organization of national and international championships, there is a lack of empirical evidence. We use data on all the matches played by national teams in all the tournaments of the FIFA Soccer World Cup (from 1930 to 2010) and the UEFA European Football Championship (from 1960 to 2012). We relate team performance (in terms of goal difference and points gained) to the respective days of rests that teams have had after their previous match, controlling for several measures of teams' abilities. Using different estimators we show that, under the current structure of major international tournaments, there are no relevant effects of enjoying different days of rest on team performance.
\end{abstract}

Keywords: Sports Economics; Soccer; Fatigue; Team Performance; World Cup; European Football Championship.

JEL classifications: L83; J4; J22; L25; C29.

\section{Introduction}

During the recent soccer European Championship held in June 2012, the Spain's coach Vicente del Bosque told the press before the semi-final against Portugal "We have two fewer days to rest than them. It is a small handicap". "Three days' rest is more than enough. The Spaniards claimed having two days is a disadvantage but, as a professional, I believe it is not an important factor," replied Portugal's captain Cristiano Ronaldo. Eventually, Spain defeated Portugal. In the same tournament, after the defeat of Italy in the Final against Spain, Italy's coach Cesare Prandelli said: “Really the only regret is that we didn't have a few extra days to recuperate. You could tell right away that they were fresher physically". The statements of Prandelli and del Bosque echoed coach Vince Lombardi's famous quote: "Fatigue makes cowards of us all".

Soccer is a physically and psychologically very demanding sport. In a match, each player on average covers a total distance of 9-12 km (Bangsbo, 1994) and performs approximately 1,350 activities, including about 220 runs at high speed (Mohr et al., 2003). Besides running, other game-related and energy-demanding activities, such as dribbling, tackling and heading, contribute to the overall demands on the player (Bangsbo, 1994; Reilly, 1997).

\footnotetext{
* Department of Economics, Statistics, and Finance, University of Calabria, Italy. E-mail address: v.scoppa@unical.it. I would like to thank Guido de Blasio, Maria De Paola, Paolo Naticchioni, Andrea Ottolina, Pier Francesco Perri, Michela Ponzo, Daniela Vuri, for useful comments and suggestions.
} 
In major European Leagues, such as Spain, England, Italy, Germany, top club teams play about sixty matches each year, adding up matches for the national League, the national Cup, Champions League or Europa League. ${ }^{1}$ Furthermore, many top players are also employed in matches played by their national teams. In the most important international tournaments, such as the World Cup or the European Championship, national teams play a match every three or four days in a short period of time.

Given the high number of matches played in modern soccer, a crucial question for the "productivity" of players and the optimal organization of national leagues and international championships is whether teams are enjoying the necessary rest between consecutive matches. ${ }^{2}$ Mostly important, if teams are not well rested, the spectacle of soccer might be spoiled: the speed, the acceleration, the ability to dribble, to change direction, to score, are seriously impaired when players are tired. Secondly, if opposing teams enjoy different periods of rest the balance could be altered and the outcome of the match could be determined by this factor more than by their respective strength and their players' abilities; the scheduling of matches would result more important than teams' abilities.

Only few papers analyze the role of fatigue in sports from an economist's point of view, and to the best of our knowledge, no empirical study investigates the impact of fatigue on team performance in soccer.

Some studies analyze the role of fatigue in the National Basketball Association (NBA). Entine and Small (2008), using data from two recent NBA seasons and exploiting the fact that visiting teams in the NBA typically enjoy fewer days of rest, show that the lack of rest is a factor contributing to explain the home court advantage, although the effect is quantitatively small.

Ashman, Bowman and Lambrinos (2010) using NBA data for 19 seasons show that the home team performed poorly when playing in consecutive days while the visiting team had a few days of rest. Moreover, the home team performed particularly bad when it traveled from west to east between consecutive games. They also show that the betting market was unable to take into account the home team's fatigue, systematically mispricing these kind of games.

Some other papers analyze whether differences in rest or in travelling times between opposing teams can contribute to explain the home field advantage (Carmichael and Thomas, 2005; Courneya and Carron, 1992; Nevill and Holder, 1999).

Oberhofer, Philippovich and Winner (2010) analyze if team performance in soccer is related to the distance from the home location and the away playing venue. They use data from German Football Premier League and show that team performance (measured in terms of scored and conceded goals) decreases with the distance to the playing venue. In the same vein, Nichols (2012) studies US National Football League matches and finds that visiting teams traveling from longer distance (and in particular from west to east, crossing at least one time zone) are more likely to lose.

\footnotetext{
${ }^{1}$ In Italy, for example, top teams play matches for the Italian League ("Serie A") - usually on week-ends - and in the interval between league matches - on Tuesday, Wednesday or Thursday - these teams play international matches for the Champions League or for the Europa League.

${ }^{2}$ For recent works analysing productivity in sport, see the introduction of Fried and Simmons (2011).
} 
In this paper we investigate the role of fatigue in soccer (football) using data on all the matches played by national teams in the most important international championships: the FIFA World Cup and the UEFA European Football Championship. ${ }^{3}$ These competitions - aimed at selecting, respectively, the best team in the World and in Europe - last about a month and during this period teams play a match every three or four days. Mainly to the aim of increasing TV audience, matches in these tournaments are typically staggered in different dates and, as a consequence, opposing teams in knock-out rounds often enjoy different days of rest. Exploiting these variations in teams' days of rest, we relate team performance in a match measured both in terms of goal difference and points gained - to the respective days of rests that teams enjoyed before the current match, controlling for several measures of teams' abilities and strength (number of matches played in international tournaments, points gained in these matches, positions in the FIFA World Ranking, being the hosting country of the tournament). We estimate several specifications with OLS and, as robustness checks, we also apply Ordered Probit and Poisson estimators.

Whereas we find that team performance is correlated to past outcomes in international tournaments and to the World Ranking and that the hosting country enjoys a considerable advantage, our findings show that there are no relevant effects of having different days of rest on team performance. The current organization of major soccer international tournaments, giving at least three days of rest between consecutive matches, is sufficient to preserve the productivity of players and the balance between teams.

The paper is organized in the following way. In Section 2 we describe the data and the Championships analyzed, providing also some preliminary evidence. In Section 3 we conduct an econometric analysis to estimate the impact of days of rest on team performance. In Section 4 we carry out some robustness checks. In Section 5 we analyze the possible existence of non-linear effects. Section 6 concludes.

\section{Data and Descriptive Statistics}

The data we use come from the matches of all the tournaments of the FIFA World Cup and the UEFA European Championship.

The FIFA soccer World Cup is an international competition among national teams to determine the best team in the world. The World Cup is the world's most widely viewed sporting event. ${ }^{4}$ The final tournament is held every four years since 1930 (except in 1942 and 1946 because of World War II). The latest editions were held in Japan and South Korea in 2002, in Germany in 2006 and in South Africa in 2010.

\footnotetext{
${ }^{3}$ FIFA (Fédération Internationale de Football Association) is the football's world governing body. UEFA is the Union of European Football Associations.

${ }^{4}$ According to the FIFA official website: "Based on viewers watching a minimum of 20 consecutive minutes of coverage, the 2010 tournament reached nearly a third of the world population with 2.2 billion viewers [...]. The average in-home global audience for each match was 188.4 million, while the highest average audience measured was for the final at 530.9 million" (http://www.fifa.com/worldcup/archive/southafrica2010).
} 
Currently, the final tournament involves 32 competing teams, playing at venues in a hosting country over a period of about a month (see Monks and Husch, 2009, for a detailed description). ${ }^{5}$ The tournament consists of several rounds of play. In the group stage, participating teams are divided into groups of four teams. ${ }^{6}$ Each team plays once against the other teams in its group. The standard points system is used (three points are awarded for a win, one point for a draw, zero points for a loss). The winner and runner-up of each group progresses to the eighth-finals, where a knockout system is used: two teams play each other once, ${ }^{7}$ the winner progresses to the next round while the loser is eliminated. This system is used in all subsequent rounds as well: the winners of the quarter-finals matches progress to the semifinals, and the winners of semifinals play in the final. The knock-out round requires a winner: if the match is a tie after 90 minutes, extra time of 30 minutes is played (in case of further tie, penalty kicks are used).

The UEFA European Football Championship is the main competition of national teams in Europe aimed to determine the best European soccer team. It is played every four years since 1960 in the evennumbered year between World Cup tournaments. The latest editions were held in Portugal in 2004, in Austria and Switzerland in 2008 and in Poland and Ukraine in 2012. The format of the European Football Championship is analogous to the World Cup, although the number of teams participating to the final tournament is typically lower (16 in the current format).

The data are available on the official sites of FIFA and UEFA. ${ }^{8}$ For each tournament (19 tournaments played for the World Cup and 14 for the European Championship) we know the year and the host country. For each match we observe the two opposing teams, the date in which it is played, the round stage, the goals scored, if extra time is played (or penalty kicks are necessary). Instead of using the standard definition of "home" and "away" team, we define the first team indicated in the official reports of FIFA or UEFA as "Team A" and the second team as "Team B".

We consider all the matches played in these championships except the opening match of each team in each tournament for whom there is no meaningful difference in days of rest between teams. As a result, we have available 739 observations, 572 from the World Cup and 167 from the European Championship. Descriptive statistics are reported in Table 1.

For organizational purposes, and in particular for increasing TV audience for important matches, matches in the World Cup and the European Championship typically are not played contemporaneously after the group stage. Therefore, many times teams face each other in knock-out rounds having played their latest match at different dates. For example, in the 2012 European Championship, Germany and Italy played against each other in the semi-final on the 28th of June 2012. However, Germany had played its quarter-final on the 22th June, while Italy had played its quarter-final on the 24th June. As a consequence, before the semi-final match, Germany had 6 days of rest while Italy had only 4 days.

\footnotetext{
${ }^{5}$ Prior to entering the final tournament, more than 200 national teams (other than the host nation that qualifies automatically) compete in a series of qualifying tournaments over a period of about 18 months.

${ }^{6}$ The allocation of teams to groups is in part the result of seeding $(8$ seeded teams based on the results obtained in the previous World Cup tournaments and on being the hosting nation) and in part the result of random draws.

${ }^{7}$ The pairings of teams depend on the group stage and on the ranking of teams in each group.

${ }^{8}$ Respectively, http://www.fifa.com/worldcup/archive/index.html and http://www.uefa.com/uefaeuro/index.html.
} 
For each match we calculate the days of rest of each team since its latest match, taking the simple difference between the date of the current match and the date of the previous match. On average, teams have 4.27 days of rest between two consecutive matches. Whereas in about half of the matches (53\%) the two opposing teams have the same days of rest, in $36 \%$ of the matches one of the teams had one more day of rest than its opponent, and in about $11 \%$ one of the teams had two or more days of rest. Our main explanatory variable is the Difference in Days of Rest, equal to Days of Rest Team A minus Days of Rest Team B.

\section{Table 1. Descriptive Statistics}

\begin{tabular}{|c|c|c|c|c|c|}
\hline Variables & Obs & Mean & Std. Dev. & Min & Max \\
\hline Days of Rest Team A & 739 & 4.271 & 1.058 & 1 & 8 \\
\hline Days of Rest Team B & 739 & 4.260 & 1.221 & 1 & 10 \\
\hline Difference in Days of Rest & 739 & 0.010 & 1.072 & -6 & 4 \\
\hline Goals Team A & 739 & 1.731 & 1.524 & 0 & 9 \\
\hline Goals Team B & 739 & 1.070 & 1.048 & 0 & 7 \\
\hline Goal Difference & 739 & 0.660 & 1.843 & -7 & 9 \\
\hline Points & 739 & 1.835 & 1.304 & 0 & 3 \\
\hline Average Points Team $\mathrm{A}^{(\mathrm{a})}$ & 739 & 1.526 & 0.646 & 0 & 3 \\
\hline Average Points Team $\mathrm{B}^{(\mathrm{a})}$ & 739 & 1.387 & 0.661 & 0 & 3 \\
\hline Average Points Difference ${ }^{(a)}$ & 739 & 0.139 & 0.815 & -3 & 3 \\
\hline \# Matches Team A ${ }^{(a)}$ & 739 & 22.88 & 21.520 & 1 & 97 \\
\hline \# Matches Team B ${ }^{(a)}$ & 739 & 18.22 & 17.430 & 1 & 98 \\
\hline \# Matches Difference ${ }^{(\mathrm{a})}$ & 739 & 4.655 & 24.40 & -88 & 92 \\
\hline Team A Host Country & 739 & 0.112 & 0.316 & 0 & 1 \\
\hline Team B Host Country & 739 & 0.060 & 0.239 & 0 & 1 \\
\hline Host Country Difference & 739 & 0.051 & 0.413 & -1 & 1 \\
\hline Extra Time Team A & 739 & 0.055 & 0.229 & 0 & 1 \\
\hline Extra Time Team B & 739 & 0.061 & 0.239 & 0 & 1 \\
\hline Extra Time Difference & 739 & -0.005 & 0.265 & -1 & 1 \\
\hline Fifa Ranking Team A & 347 & 17.98 & 16.35 & 1 & 105 \\
\hline Fifa Ranking Team B & 347 & 19.55 & 15.46 & 1 & 105 \\
\hline Fifa Ranking Difference & 347 & -1.571 & 22.53 & -102 & 96 \\
\hline Fifa Points Team A & 347 & 573.3 & 407.0 & 35 & 1611 \\
\hline Fifa Points Team B & 347 & 568.4 & 408.4 & 35 & 1611 \\
\hline Fifa Points Difference & 347 & 4.963 & 201.6 & -936 & 964 \\
\hline
\end{tabular}

Notes: The data are from all the matches (except the opening match of each team in the tournament) of World Cup (1930-2010) (572 matches) and European Championship (1960-2012) (167 matches).

(a) Calculated considering all the past matches (excluding the current match) played in the championship considered.

A second measure of fatigue that we consider is related to the occurrence for a team of playing extra time in the previous match. We build the dummy variable Extra Time Team A equal to 1 if in the previous match Team A played extra time and zero otherwise. Similarly, we build Extra Time Team B. We then take the difference between these dummies, building the variable Extra Time Difference.

We measure team performance in a match in two different ways: Goal Difference, calculated as Goals Team A minus Goals Team B and the number of Points gained (by Team A). In the latter case, we attribute three points if a team wins a game, one point in case of draw and zero points for a loss, even in knock-out matches in which points are not formally assigned. We consider the final result at the end of 90 minutes or at the end of 120 minutes in case of extra time (regardless of penalty kicks outcome). All our variables of performance are defined as the difference between Team A and Team B. 
To control for the respective abilities or strengths of national teams, we build the variable Average Points gained by a team in all the past matches of, respectively, the World Cup and the European Championship before the current match. Then, we determine the Average Points Difference (between Team A and Team B) taking the difference between the Average Points Team A minus the Average Points Team B.

Moreover, we determine the Number of Matches played in past in each championship (before the current match). Playing a higher number of matches in a championship implies that a team has qualified for the final tournament more times and/or that it has progressed in the tournament for a higher number of rounds. As above, we calculate the Number of Matches Difference.

As a further measure of quality of a team, we calculate the number of points gained in each tournament prior to the current match and calculate the difference between the two opposing teams, building the variable Difference in Points in the Tournament.

We also control for the fact that one of two teams is the host country. We build a variable Host Country Difference equal to zero if neither team is the host country, equal to +1 if the Team $\mathrm{A}$ is the host country and equal to -1 if the Team B is the host country.

Finally, as an alternative measure of abilities of teams, we use the FIFA-Coca Cola World Ranking, which is a very accurate ranking system for national teams. ${ }^{9}$ The national teams are awarded points on the basis of the results obtained in international matches played in the latest four years; more recent results and more important matches are more heavily weighted. The ranking is updated approximately on a monthly basis. To avoid problems of reverse causality, we attach to each team for each tournament the respective most recent FIFA World ranking dating about a month before the event considered. For example, for the matches of the World Cup played in South Africa in June 2010, we attach to each team the FIFA ranking of May 2010. The top team has a ranking of 1, the second best team has a ranking of 2 and so on. We use, alternatively, both the points accumulated by teams and their rankings.

Unfortunately, the FIFA World Ranking has been introduced only in 1993 and therefore when we control for this variable we can only use the observations starting since 1994 (leaving us with 347 observations). However, we find that the FIFA World Ranking is highly correlated to our alternative measures of strengths of national teams (for example, the correlation with Average Points Difference is $\rho=-$ $0.48, p$-value $=0.000$ ), reassuring us that the latter are good proxies of teams' quality.

\section{Difference in Days of Rest and Performance of Teams}

In this Section we carry out an econometric analysis of the impact of days of rest on team performance.

We first consider Goal Difference as dependent variable and estimate a number of specifications using an OLS estimator. Results of estimates are reported in Table 2. It should be noted that Goal Difference is positive if Team A scored more goals than Team B and, similarly, Difference in Days of Rest is positive if Team A had more rest than Team B.

\footnotetext{
${ }^{9}$ The official site for the FIFA world ranking is: http://www.fifa.com/worldranking/rankingtable/index.html
} 
In column (1) we simply regress Goal Difference on the Difference in Days of Rest. We find that the difference in rest has no impact on team performance, although the coefficient is positive ( $p$-value $=0.29$ ). However, these estimates could be biased since any difference in rest between teams could be correlated to teams' abilities or to other factors affecting team performance.

To this aim, in an auxiliary regression (not reported) we investigate if the days of rest of a team are independent from other observable variables: we find that the days of rest of a team tend to be positively correlated to the variables measuring team's quality and to the dummy Host Country, implying that probably as a result of seeding and of the final rankings in group stage - stronger teams and the home team have a higher probability of enjoying of more rest between matches.

Therefore, to avoid any bias in the estimations because of omitted variables, we need to control for a number of variables that could determine team performance and could be possibly related to our variable of interest, Difference in Days of Rest.

In column (2) we control for two variables aimed to capture any difference in the quality of opposing teams: number of matches played in the past tournaments in the World Cup or in the European Championship (respectively, according to the tournament considered) and the average points realized in these championships. The Average Points Difference has a positive and strong impact on team performance, implying that better teams (according to their past outcomes) score more goals and concede less goals to opponents: if Team A has obtained on average one point more than Team B in past matches in a championship, then the expected difference in goal is about 0.42. Similarly, teams with a higher number of matches played in past international championships attain better outcomes. Both these variables are highly statistically significant (at the 1 percent level). Crucially, once we control for teams' quality, we find that Difference in Days of Rest has no impact whatsoever on team performance.

In column (3) we control for the variable Host Country Difference to take into account the fact that one of the teams is the host country. This variable should control for the well-known "home advantage", which, as shown in many studies, is strong in many sports and in soccer in particular, due to psychological reasons, social pressure by the crowd, possible favouritism of referees and so on (see Carmichael and Thomas, 2005, and Scoppa, 2008). Host Country Difference has a strong impact on team performance: our estimates show that a team obtains 0.66 goals more than its opponent if the match is played in its own country. Again, the Difference in Days of Rest has no effect on team performance.

In column (4) we control for another variable that proxies for the fatigue of players: Extra Time Difference, which is equal to one if Team A has played extra time in the previous match (or - 1 if Team B has played extra time). As expected, playing Extra Time has a negative effect on team performance, although the effect is not statistically significant at conventional levels ( $p$-value $=0.22$ ).

To investigate if days of rest have a different impact in the World Cup with respect to the European Championship - given that in the World Cup more rounds are typically played - in column (5) of Table 2 we control for a dummy World Cup (equal to one for World Cup and 0 for European Championship matches) and an interaction variable (Difference in Days of Rest)*(World Cup). Results show that the days of rest has 
no impact on performance neither in the European Championship (the coefficient is -0.0682 , with a $p$-value of 0.67 ), nor in the World Cup (the corresponding coefficient is $-0.0682+0.0898=0.021$, with a $p$-value of $0.75)$.

Finally, in column (6) of Table 2, as further controls, we include team fixed effects (76 teams are present). Also in this case, Difference in Day of Rest has no significant effect on the Goal Difference. ${ }^{10}$

Table 2. Team Performance and Rest. OLS Estimates. Dependent Variable: Goal Difference

\begin{tabular}{|c|c|c|c|c|c|c|}
\hline & (1) & (2) & (3) & (4) & (5) & (6) \\
\hline Difference in Days of Rest & $\begin{array}{c}0.0716 \\
(0.0680)\end{array}$ & $\begin{array}{c}0.0061 \\
(0.0661)\end{array}$ & $\begin{array}{l}-0.0054 \\
(0.0642)\end{array}$ & $\begin{array}{l}-0.0055 \\
(0.0642)\end{array}$ & $\begin{array}{l}-0.0682 \\
(0.1584)\end{array}$ & $\begin{array}{l}-0.0250 \\
(0.0683)\end{array}$ \\
\hline Average Points Difference & & $\begin{array}{c}0.4177 * * * \\
(0.1021)\end{array}$ & $\begin{array}{c}0.4485^{* * * *} \\
(0.1023)\end{array}$ & $\begin{array}{c}0.4457 * * * \\
(0.1023)\end{array}$ & $\begin{array}{c}0.4324 * * * \\
(0.1017)\end{array}$ & $\begin{array}{c}0.3359 * * * \\
(0.1110)\end{array}$ \\
\hline \# Matches Difference & & $\begin{array}{c}0.0149 * * * \\
(0.0029)\end{array}$ & $\begin{array}{c}0.0144 * * * \\
(0.0028)\end{array}$ & $\begin{array}{c}0.0143^{* * * *} \\
(0.0028)\end{array}$ & $\begin{array}{c}0.0133^{* * * *} \\
(0.0029)\end{array}$ & $\begin{array}{c}0.0074 * * \\
(0.0035)\end{array}$ \\
\hline Host Country Difference & & & $\begin{array}{c}0.6609 * * * \\
(0.1513)\end{array}$ & $\begin{array}{c}0.6632 * * * \\
(0.1522)\end{array}$ & $\begin{array}{c}0.6571 * * * \\
(0.1515)\end{array}$ & $\begin{array}{c}0.7187 * * * \\
(0.1599)\end{array}$ \\
\hline Extra Time Difference & & & & $\begin{array}{l}-0.2666 \\
(0.2183)\end{array}$ & $\begin{array}{l}-0.2614 \\
(0.2210)\end{array}$ & $\begin{array}{l}-0.2870 \\
(0.2291)\end{array}$ \\
\hline World Cup & & & & & $\begin{array}{c}0.4162 * * * \\
(0.1479)\end{array}$ & \\
\hline (Difference in Days of Rest)*World Cup & & & & & $\begin{array}{c}0.0898 \\
(0.1718)\end{array}$ & \\
\hline Constant & $\begin{array}{c}0.6596 * * * \\
(0.0679)\end{array}$ & $\begin{array}{c}0.5329 * * * \\
(0.0645)\end{array}$ & $\begin{array}{c}0.4969 * * * \\
(0.0641)\end{array}$ & $\begin{array}{c}0.4964 * * * \\
(0.0641)\end{array}$ & $\begin{array}{c}0.1832 \\
(0.1276)\end{array}$ & $\begin{array}{c}0.5410 * * * \\
(0.0635)\end{array}$ \\
\hline Team Fixed Effects & NO & NO & NO & NO & NO & YES \\
\hline Observations & 739 & 739 & 739 & 739 & 739 & 739 \\
\hline Adjusted R-squared & 0.000 & 0.101 & 0.121 & 0.121 & 0.129 & 0.173 \\
\hline
\end{tabular}

Notes: The Table reports OLS estimates. The dependent variable is Goal Difference (Goals Team A minus Goals Team B). All the differences are defined as the outcome of Team A minus the outcome of Team B. Standard errors (reported in parentheses) are corrected for heteroskedasticity. The symbols $* * *, * *, *$ indicate that coefficients are statistically significant, respectively, at the 1,5 , and 10 percent level.

As an alternative measure of Goal Difference, we now use as dependent variable the Points gained (by Team A). We firstly consider the points gained as a cardinal variable using an OLS estimator. In the next Section, we deal with the ordinal nature of this variable estimating an Ordered Probit model.

In Table 3 we estimate the same specifications of Table 2. In column (1) we find that the differences in days of rest has a positive, although small, impact on Points (significant at the 10 percent level): a team with one more day of rest obtains about 0.075 points more. However, as explained above, this result is probably due to the bias deriving from the omission of variables accounting for teams' quality. In fact, in column (2) in which we control for our two measures of teams' relative strength (Average Points Difference and \# Matches Difference), we find that the Difference in Days of Rest is no more statistically significant. The variables capturing teams' qualities, on the other hand, attract positive coefficients and are highly statistically significant. In column (3), controlling for the dummy for the hosting country, we confirm that the gap in days of rest has no impact on team performance, while the Host Country Difference has a strong

\footnotetext{
${ }^{10}$ Furthermore, we also control for the points that teams obtained in the past matches in the current tournaments, disregarding the outcomes they obtained in previous tournaments, Difference in Points in the Tournament. We find very similar results (regression not reported for brevity).
} 
positive effect on team's points, equal to 0.426 points. In column (4) we find that playing extra time in the previous match has a negative impact on the points gained by a team but the effect, although not small $(-0.233)$, is not statistically significant at conventional levels ( $p$-value $=0.199)$. Again, we find that any difference in days of rest has no effect on team performance. This result is also confirmed in column (5) where we investigate a possible heterogeneous impact of rest between World Cup and European Championship tournaments: both the effects are near zero and very far from statistical significance. Finally, Difference in Day of Rest has no significant effect in column (6) where we control for team fixed effects.

Table 3. Team Performance and Rest. OLS Estimates. Dependent Variable: Points

\begin{tabular}{|c|c|c|c|c|c|c|}
\hline & $(1)$ & $(2)$ & (3) & $(4)$ & $(5)$ & $(6)$ \\
\hline Difference in Days of Rest & $\begin{array}{l}0.0747 * \\
(0.0436)\end{array}$ & $\begin{array}{c}0.0345 \\
(0.0426)\end{array}$ & $\begin{array}{c}0.0271 \\
(0.0423)\end{array}$ & $\begin{array}{c}0.0271 \\
(0.0424)\end{array}$ & $\begin{array}{c}-0.0162 \\
(0.1136)\end{array}$ & $\begin{array}{c}0.0073 \\
(0.0457)\end{array}$ \\
\hline Average Points Difference & & $\begin{array}{c}0.1642 * * * \\
(0.0631)\end{array}$ & $\begin{array}{c}0.1841 * * * \\
(0.0630)\end{array}$ & $\begin{array}{c}0.1816 * * * \\
(0.0629)\end{array}$ & $\begin{array}{c}0.1689 * * * \\
(0.0627)\end{array}$ & $\begin{array}{c}0.1052 \\
(0.0704)\end{array}$ \\
\hline \# Matches Difference & & $\begin{array}{c}0.0115 * * * \\
(0.0021)\end{array}$ & $\begin{array}{c}0.0112 * * * \\
(0.0021)\end{array}$ & $\begin{array}{c}0.0110^{* * * *} \\
(0.0021)\end{array}$ & $\begin{array}{c}0.0102 * * * \\
(0.0021)\end{array}$ & $\begin{array}{c}0.0053 * * \\
(0.0026)\end{array}$ \\
\hline Host Country Difference & & & $\begin{array}{c}0.4260 * * * \\
(0.1105)\end{array}$ & $\begin{array}{c}0.4279 * * * \\
(0.1116)\end{array}$ & $\begin{array}{c}0.4208 * * * \\
(0.1107)\end{array}$ & $\begin{array}{c}0.4620 * * * \\
(0.1190)\end{array}$ \\
\hline Extra Time Difference & & & & $\begin{array}{c}-0.2332 \\
(0.1813)\end{array}$ & $\begin{array}{l}-0.2272 \\
(0.1823)\end{array}$ & $\begin{array}{l}-0.2019 \\
(0.1857)\end{array}$ \\
\hline World Cup & & & & & $\begin{array}{c}0.4051 * * * \\
(0.1169)\end{array}$ & \\
\hline (Difference in Days of Rest)*World Cup & & & & & $\begin{array}{c}0.0663 \\
(0.1221)\end{array}$ & \\
\hline Constant & $\begin{array}{c}1.8341 * * * \\
(0.0479)\end{array}$ & $\begin{array}{c}1.7583 * * * \\
(0.0480)\end{array}$ & $\begin{array}{c}1.7351 * * * \\
(0.0482)\end{array}$ & $\begin{array}{c}1.7347 * * * \\
(0.0482)\end{array}$ & $\begin{array}{c}1.4292 * * * \\
(0.1037)\end{array}$ & $\begin{array}{c}1.7705 * * * \\
(0.0489) \\
\text { Team Fixed } \\
\text { Effects } \\
\end{array}$ \\
\hline Observations & 739 & 739 & 739 & 739 & 739 & 739 \\
\hline Adjusted R-squared & 0.002 & 0.074 & 0.091 & 0.092 & 0.107 & 0.116 \\
\hline
\end{tabular}

Notes: The Table reports OLS estimates. The dependent variable is Points gained by Team A. All the differences are defined as the outcome of Team A minus the outcome of Team B. Standard errors (reported in parentheses) are corrected for heteroskedasticity. The symbols $* * *, * * *$ indicate that coefficients are statistically significant, respectively, at the 1,5 , and 10 percent level.

A possible concern with previous estimates is that the measures of teams' abilities used might be rather imperfect, since they take into account performance of teams in the past tournaments, while teams' current strength could be quite different. To consider this aspect, we take advantage of the FIFA World Ranking, reflecting teams' quality as evaluated about one month before each tournament. As this ranking is available only since 1993, we only use tournaments starting since 1994 and we end up with 347 observations.

We replicate specifications (2) and (4) of Table 2 and Table 3, simply substituting the two variables of teams' abilities firstly with FIFA Ranking Difference and then with FIFA Points Difference. Estimations results are reported in Table 4. In columns (1)-(3) we use as dependent variable Goal Difference, while we use Points in columns (4)-(6).

In all the specifications we find that the Difference in Days of Rest has no impact on team performance. As expected, the ranking difference has a strong negative impact on Goal Difference and on Points: if the ranking difference is positive (that is, if team A is ranked lower than team B), this implies that the performance of team A is predicted to be worse than the performance of team B. In columns (3) and (6) 
instead of teams' ranks we use simply the number of points accumulated in the FIFA World Ranking. The qualitative results are the same. ${ }^{11}$

Furthermore, the estimates on a sample considering only the matches played in more recent times (since 1994) show that our results of no impact of rest on team performance are valid also for the current way of playing soccer that, according to experts and spectators, is played with much higher intensity and at fast pace than in the past.

Table 4. OLS Estimates. Controlling for teams' FIFA World rankings

\begin{tabular}{|c|c|c|c|c|c|c|}
\hline & \multicolumn{3}{|c|}{ Goal Difference } & \multicolumn{3}{|c|}{ Points } \\
\hline & $(1)$ & (2) & (3) & (4) & $(5)$ & $(6)$ \\
\hline Difference in Days of Rest & $\begin{array}{l}-0.0540 \\
(0.0970)\end{array}$ & $\begin{array}{l}-0.1045 \\
(0.0952)\end{array}$ & $\begin{array}{l}-0.0536 \\
(0.0970)\end{array}$ & $\begin{array}{c}-0.0174 \\
(0.0860)\end{array}$ & $\begin{array}{l}-0.0492 \\
(0.0857)\end{array}$ & $\begin{array}{l}-0.0222 \\
(0.0847)\end{array}$ \\
\hline FIFA Ranking Difference & $\begin{array}{c}-0.0282 * * * \\
(0.0046)\end{array}$ & $\begin{array}{c}-0.0338 * * * \\
(0.0045)\end{array}$ & & $\begin{array}{c}-0.0162 * * * \\
(0.0028)\end{array}$ & $\begin{array}{c}-0.0193 * * * \\
(0.0029)\end{array}$ & \\
\hline FIFA Points Difference & & & $\begin{array}{c}0.0031 * * * \\
(0.0005)\end{array}$ & & & $\begin{array}{c}0.0020 * * * \\
(0.0003)\end{array}$ \\
\hline Host Country Difference & & $\begin{array}{c}1.1099 * * * \\
(0.2422)\end{array}$ & $\begin{array}{c}0.8936 * * * \\
(0.2407)\end{array}$ & & $\begin{array}{c}0.6505 * * * \\
(0.1859)\end{array}$ & $\begin{array}{c}0.5595 * * * \\
(0.1854)\end{array}$ \\
\hline Extra Time Difference & & $\begin{array}{l}-0.1344 \\
(0.2924)\end{array}$ & $\begin{array}{l}-0.1704 \\
(0.2768)\end{array}$ & & $\begin{array}{l}-0.2082 \\
(0.2554)\end{array}$ & $\begin{array}{l}-0.2134 \\
(0.2437)\end{array}$ \\
\hline Constant & $\begin{array}{c}0.1152 \\
(0.0877)\end{array}$ & $\begin{array}{c}0.0931 \\
(0.0850)\end{array}$ & $\begin{array}{c}0.1335 \\
(0.0885)\end{array}$ & $\begin{array}{c}1.4187 * * * \\
(0.0692)\end{array}$ & $\begin{array}{c}1.4076 * * * \\
(0.0684)\end{array}$ & $\begin{array}{c}1.4287 * * * \\
(0.0688)\end{array}$ \\
\hline Observations & 347 & 347 & 347 & 347 & 347 & 347 \\
\hline Adjusted R-squared & 0.125 & 0.171 & 0.118 & 0.069 & 0.095 & 0.086 \\
\hline
\end{tabular}

Notes: The Table reports OLS estimates. The dependent variable is Goal Difference (Goals Team A minus Goals Team B) in columns (1)-(3), Points gained by Team A in columns (4)-(6). All the differences are defined as the outcome of Team A minus the outcome of Team B. Standard errors (reported in parentheses) are corrected for heteroskedasticity. The symbols ***, **, * indicate that coefficients are statistically significant, respectively, at the 1,5 , and 10 percent level.

\section{Robustness Checks: Ordered Probit and Poisson Estimators}

In this Section, as robustness checks for the evaluation of the impact on team performance of days of rest, instead of using the simple OLS estimator used in the previous estimates, we use two alternative estimators (Ordered Probit and Bivariate Poisson) that are more appropriate for the type of dependent variables we use.

Firstly, to take into account the ordinal nature of the dependent variable Points originated from win, draw, or loss, we estimate an Ordered Probit Model of team performance. In Table 5, we report Ordered Probit estimates considering as dependent variable the final result of the game. In column (1) without any controls, we show that there is a weak positive and significant effect (at the 10 percent level) of days of rest on team performance. However, when in column (2) we add controls for the past performance of teams (Average Points Difference and Number of Matches Difference), which turn out to be highly statistically significant, we find that Difference in Days of Rest is far from being significant ( $p$-value=0.430). The result of no impact of the rest difference is confirmed when in column (3) we also control for Host Country Difference (positive and statistically significant) and when in column (4) we add control for any difference in

\footnotetext{
${ }^{11}$ We also use together FIFA Ranking Difference, Average Points Difference and \# Matches Difference, obtaining very similar results.
} 
Extra Time played by teams in their previous matches (negative, but not significant at conventional levels). Finally, we get the same result in column (5) in which we use FIFA Ranking Difference as a measure of teams' quality instead of Average Points Difference and \# Matches Difference.

All in all, the results of the Ordered Probit model fully confirm those found using OLS.

Table 5. Days of Rest and Team Performance. Ordered Probit Estimates on Points

\begin{tabular}{|c|c|c|c|c|c|}
\hline & (1) & (2) & (3) & (4) & (5) \\
\hline Difference in Days of Rest & $\begin{array}{l}0.0701 * \\
(0.0402)\end{array}$ & $\begin{array}{c}0.0320 \\
(0.0406)\end{array}$ & $\begin{array}{c}0.0263 \\
(0.0406)\end{array}$ & $\begin{array}{c}0.0265 \\
(0.0407)\end{array}$ & $\begin{array}{l}-0.0392 \\
(0.0774)\end{array}$ \\
\hline Average Points Difference & & $\begin{array}{c}0.1497 * * \\
(0.0617)\end{array}$ & $\begin{array}{c}0.1689 * * * \\
(0.0624)\end{array}$ & $\begin{array}{c}0.1666 \text { *** } \\
(0.0623)\end{array}$ & \\
\hline \# Matches Difference & & $\begin{array}{c}0.0120 * * * \\
(0.0024)\end{array}$ & $\begin{array}{c}0.0119 * * * \\
(0.0024)\end{array}$ & $\begin{array}{c}0.0118 * * * \\
(0.0024)\end{array}$ & \\
\hline Host Country Difference & & & $\begin{array}{c}0.4308 * * * \\
(0.1133)\end{array}$ & $\begin{array}{c}0.4313 \text { *** } \\
(0.1143)\end{array}$ & $\begin{array}{c}0.6193 * * * \\
(0.1870)\end{array}$ \\
\hline Extra Time Difference & & & & $\begin{array}{l}-0.2369 \\
(0.1785)\end{array}$ & $\begin{array}{l}-0.2409 \\
(0.2399)\end{array}$ \\
\hline FIFA Ranking Difference & & & & & $\begin{array}{c}-0.0185 * * * \\
(0.0032)\end{array}$ \\
\hline Cut-off 1 & $\begin{array}{c}-0.7003 * * * \\
(0.0505)\end{array}$ & $\begin{array}{c}-0.6614 * * * \\
(0.0513)\end{array}$ & $\begin{array}{c}-0.6470 * * * \\
(0.0516)\end{array}$ & $\begin{array}{c}-0.6478 * * * \\
(0.0516)\end{array}$ & $\begin{array}{c}-0.3431 * * * \\
(0.0707)\end{array}$ \\
\hline Cut-off 2 & $\begin{array}{c}-0.0963 * * \\
(0.0463)\end{array}$ & $\begin{array}{l}-0.0193 \\
(0.0486)\end{array}$ & $\begin{array}{c}0.0046 \\
(0.0494)\end{array}$ & $\begin{array}{c}0.0053 \\
(0.0495)\end{array}$ & $\begin{array}{c}0.3005 * * * \\
(0.0708)\end{array}$ \\
\hline Observations & 739 & 739 & 739 & 739 & 347 \\
\hline Pseudo R-squared & 0.002 & 0.044 & 0.055 & 0.056 & 0.055 \\
\hline
\end{tabular}

Notes: The Table reports Ordered Probit estimates. The dependent variable is Points gained by Team A. All the differences are defined as the outcome of Team A minus the outcome of Team B. Standard errors (reported in parentheses) are corrected for heteroskedasticity. The symbols $* * *, * * *$ indicate that coefficients are statistically significant, respectively, at the 1,5 , and 10 percent level.

As a further robustness check, instead of using Goal Difference, we measure team performance with the number of Goals Scored and the number of Goals Conceded per game. These two measures are aimed at describing respectively the offensive and defensive capabilities of a team (see also Koning, 2003).

The separate analysis for Goals Scored and Goals Conceded is also interesting because if some categories of players are more affected by fatigue than others (for example, it seems that forward players tend to provide more effort than defenders or goalkeeper in a match, see Mohr et al., 2003), then the number of goals scored could be more affected by the difference in rest rather than the number of goals conceded.

We estimate the determinants of Goals Scored and Goals Conceded using a Poisson estimator given that the latter are count variables and take on non-negative integer values. Moreover, since these variables may be correlated, we estimate a Bivariate Poisson model which takes into account possible correlation of residuals in the two equations (see Karlis and Ntzoufras, 2003). ${ }^{12}$

In Table 6 we report estimation results replicating the specifications of Table 5. Panel (a) reports results for Goals Scored and Panel (b) for Goals Conceded. The results show that, regardless of the specification, Difference in Days of Rest has no impact neither on Goals scored nor on Goals conceded.

\footnotetext{
${ }^{12}$ Since it is reasonable to think that the determinants of goals scored and goals conceded are not different, we obtain identification through the functional form, without imposing an exclusion restriction.
} 
Table 6. The Effect of Rest on Goals scored and Conceded. Bivariate Poisson Estimates

\begin{tabular}{|c|c|c|c|c|c|}
\hline \multicolumn{6}{|c|}{ Panel (a) - Goals scored } \\
\hline & $(1)$ & $(2)$ & (3) & (4) & $(5)$ \\
\hline Difference in Days of Rest & $\begin{array}{c}0.0200 \\
(0.0362)\end{array}$ & $\begin{array}{c}0.0007 \\
(0.0364)\end{array}$ & $\begin{array}{l}-0.0043 \\
(0.0366)\end{array}$ & $\begin{array}{l}-0.0041 \\
(0.0366)\end{array}$ & $\begin{array}{l}-0.0734 \\
(0.0562)\end{array}$ \\
\hline Average Points Difference & & $\begin{array}{c}0.2227 * * * \\
(0.0441)\end{array}$ & $\begin{array}{c}0.2361 * * * \\
(0.0444)\end{array}$ & $\begin{array}{c}0.2342 * * * \\
(0.0444)\end{array}$ & \\
\hline \# Matches Difference & & $\begin{array}{l}0.0020^{*} \\
(0.0012)\end{array}$ & $\begin{array}{c}0.002 \\
(0.0012)\end{array}$ & $\begin{array}{c}0.0019 \\
(0.0012)\end{array}$ & \\
\hline Host Country Difference & & & $\begin{array}{c}0.2470 * * * \\
(0.0795)\end{array}$ & $\begin{array}{c}0.2477 * * * \\
(0.0804)\end{array}$ & $\begin{array}{c}0.5360 * * * \\
(0.1259)\end{array}$ \\
\hline Extra Time Difference & & & & $\begin{array}{l}-0.1658 \\
(0.1041)\end{array}$ & $\begin{array}{l}-0.0168 \\
(0.1718)\end{array}$ \\
\hline FIFA Ranking Difference & & & & & $\begin{array}{c}-0.0129 * * * \\
(0.0021)\end{array}$ \\
\hline Constant & $\begin{array}{c}0.5481 * * * \\
(0.0324)\end{array}$ & $\begin{array}{c}0.4865 * * * \\
(0.0335)\end{array}$ & $\begin{array}{c}0.4670 * * * \\
(0.0348)\end{array}$ & $\begin{array}{c}0.4658^{* * * *} \\
(0.0347)\end{array}$ & $\begin{array}{c}0.2232 * * * \\
(0.0493)\end{array}$ \\
\hline \multicolumn{6}{|c|}{ Panel (b) - Goals conceded } \\
\hline & $(1)$ & (2) & (3) & (4) & $(5)$ \\
\hline Difference in Days of Rest & $\begin{array}{l}-0.0344 \\
(0.0365)\end{array}$ & $\begin{array}{c}-0.004 \\
(0.0353)\end{array}$ & $\begin{array}{c}-0.001 \\
(0.0346)\end{array}$ & $\begin{array}{l}-0.0011 \\
(0.0346)\end{array}$ & $\begin{array}{c}0.0120 \\
(0.0558)\end{array}$ \\
\hline Average Points Difference & & $\begin{array}{l}-0.0301 \\
(0.0531)\end{array}$ & $\begin{array}{l}-0.0393 \\
(0.053)\end{array}$ & $\begin{array}{l}-0.0395 \\
(0.0530)\end{array}$ & \\
\hline \# Matches Difference & & & $\begin{array}{c}-0.0104 * * * \\
(0.0016)\end{array}$ & $\begin{array}{c}-0.0104 * * * \\
(0.0016)\end{array}$ & \\
\hline Host Country Difference & & & $\begin{array}{r}-0.2189 * * * \\
(0.083)\end{array}$ & $\begin{array}{c}-0.2189 * * * \\
(0.0831)\end{array}$ & $\begin{array}{c}-0.3323 * * * \\
(0.1271)\end{array}$ \\
\hline Extra Time Difference & & & & $\begin{array}{l}-0.0272 \\
(0.1153)\end{array}$ & $\begin{array}{c}0.1023 \\
(0.1404)\end{array}$ \\
\hline FIFA Ranking Difference & & & & & $\begin{array}{c}0.0132 * * * \\
(0.0020)\end{array}$ \\
\hline Constant & $\begin{array}{l}0.0677 * \\
(0.0361)\end{array}$ & $\begin{array}{c}-0.0107 * * * \\
(0.0016)\end{array}$ & $\begin{array}{c}0.0928 * * * \\
-0.0348\end{array}$ & $\begin{array}{c}0.0927 * * * \\
(0.0348)\end{array}$ & $\begin{array}{c}0.1519 * * * \\
(0.0476)\end{array}$ \\
\hline Rho $(\rho)$ (p-value) & $\begin{array}{c}0.0077 \\
(0.8338)\end{array}$ & $\begin{array}{c}0.0545 \\
(0.1381)\end{array}$ & $\begin{array}{c}0.0669 \\
(0.0689)\end{array}$ & $\begin{array}{c}0.0667 \\
(0.0699)\end{array}$ & $\begin{array}{l}-0.0297 \\
(0.5805)\end{array}$ \\
\hline Observations & 739 & 739 & 739 & 739 & 347 \\
\hline
\end{tabular}

Notes: The Table reports Bivariate Poisson estimates. The dependent variable in Panel (a) is Goals scored by team A. The dependent variable in Panel (b) is Goals conceded by team A. All the differences are defined as the outcome of Team A minus the outcome of Team B. Standard errors (reported in parentheses) are corrected for heteroskedasticity. The symbols ***, **, * indicate that coefficients are statistically significant, respectively, at the 1,5 , and 10 percent level. 


\section{Investigating the Existence of Non-Monotonic Effects of Rest}

In this Section we investigate whether the effect of days of rest is non-monotonic. In fact, it could be that a difference of two or more days of rest is important in affecting performance, while a difference of only one day is not relevant.

To this aim, we build four new dummy variables: "Rest $<=-2$ " if Team A had two (or more in absolute terms) fewer days of rest than Team B; "Rest $=-1$ " if Team A had one fewer day of rest than Team $\mathrm{B}$; "Rest $=+1$ " if Team A had one day more of rest than Team B; "Rest $>=+2$ " if Team A had two (or more) days of rest than Team B. The reference category is that the two opposing teams had the same rest.

In columns (1) and (2) of Table 7 we estimate with OLS the impact on Goal Difference using the specifications with a full range of controls. None of the dummies representing differences in days of rest between the two opposing teams is statistically significant. Furthermore, we are not able to reject the hypothesis that these four dummies are jointly equal to zero $(F=0.25 ; p$-value $=0.909)$.

In columns (3) and (4) we replicate the same specifications using as dependent variable Points and estimate with OLS, while in columns (5) and (6) we estimate Ordered Probit models. Our results are confirmed in all the specifications: differences in days of rest are never significant in explaining team performance.

Table 7. Investigating Non-Monotonic Effects of Rest. OLS and Ordered Probit Estimates

\begin{tabular}{|c|c|c|c|c|c|c|}
\hline & $\begin{array}{c}(1) \\
\text { Goal } \\
\text { Difference } \\
\text { OLS }\end{array}$ & $\begin{array}{c}(2) \\
\text { Goal } \\
\text { Difference } \\
\text { OLS }\end{array}$ & $\begin{array}{c}(3) \\
\text { Points } \\
\text { OLS }\end{array}$ & $\begin{array}{c}\text { (4) } \\
\text { Points } \\
\text { OLS }\end{array}$ & $\begin{array}{c}\text { Ordered } \\
\text { Probit } \\
\end{array}$ & $\begin{array}{c}\text { Ordered } \\
\text { Probit } \\
\end{array}$ \\
\hline Rest $<=-2$ & $\begin{array}{c}-0.0110 \\
(0.3574)\end{array}$ & $\begin{array}{c}0.0062 \\
(0.5691)\end{array}$ & $\begin{array}{c}-0.1938 \\
(0.2233)\end{array}$ & $\begin{array}{c}0.4166 \\
(0.4425)\end{array}$ & $\begin{array}{c}-0.1514 \\
(0.2020)\end{array}$ & $\begin{array}{c}0.3178 \\
(0.4179)\end{array}$ \\
\hline Rest $=-1$ & $\begin{array}{c}-0.0431 \\
(0.1681)\end{array}$ & $\begin{array}{c}-0.0628 \\
(0.2221)\end{array}$ & $\begin{array}{c}0.0525 \\
(0.1255)\end{array}$ & $\begin{array}{c}0.0130 \\
(0.1895)\end{array}$ & $\begin{array}{c}0.0579 \\
(0.1207)\end{array}$ & $\begin{array}{c}0.0035 \\
(0.1703)\end{array}$ \\
\hline Rest $=+1$ & $\begin{array}{l}-0.1589 \\
(0.1813)\end{array}$ & $\begin{array}{c}-0.2975 \\
(0.2582)\end{array}$ & $\begin{array}{c}-0.1362 \\
(0.1254)\end{array}$ & $\begin{array}{c}-0.0852 \\
(0.1997)\end{array}$ & $\begin{array}{l}-0.1074 \\
(0.1186)\end{array}$ & $\begin{array}{l}-0.0762 \\
(0.1810)\end{array}$ \\
\hline Rest $>=+2$ & $\begin{array}{c}0.0681 \\
(0.2380)\end{array}$ & $\begin{array}{c}-0.3687 \\
(0.2814)\end{array}$ & $\begin{array}{c}0.2225 \\
(0.1831)\end{array}$ & $\begin{array}{c}0.0835 \\
(0.2986)\end{array}$ & $\begin{array}{c}0.2346 \\
(0.1949)\end{array}$ & $\begin{array}{c}0.0627 \\
(0.2755)\end{array}$ \\
\hline Average Points Difference & $\begin{array}{c}0.4519 * * * \\
(0.1031)\end{array}$ & & $\begin{array}{c}0.1850 * * * \\
(0.0637)\end{array}$ & & $\begin{array}{c}0.1686 * * * \\
(0.0629)\end{array}$ & \\
\hline \# Matches Difference & $\begin{array}{c}0.0145 * * * \\
(0.0028)\end{array}$ & & $\begin{array}{c}0.0115 * * * \\
(0.0021)\end{array}$ & & $\begin{array}{c}0.0122 * * * \\
(0.0024)\end{array}$ & \\
\hline Host Country Difference & $\begin{array}{c}0.6716 * * * \\
(0.1524)\end{array}$ & $\begin{array}{c}1.0867 * * * \\
(0.2432)\end{array}$ & $\begin{array}{c}0.4403 * * * \\
(0.1110)\end{array}$ & $\begin{array}{c}0.6727 * * * \\
(0.1892)\end{array}$ & $\begin{array}{c}0.4453 * * * \\
(0.1138)\end{array}$ & $\begin{array}{c}0.6370 * * * \\
(0.1898)\end{array}$ \\
\hline Extra Time Difference & $\begin{array}{l}-0.2575 \\
(0.2174)\end{array}$ & $\begin{array}{l}-0.1125 \\
(0.3008)\end{array}$ & $\begin{array}{l}-0.2201 \\
(0.1831)\end{array}$ & $\begin{array}{l}-0.2266 \\
(0.2575)\end{array}$ & $\begin{array}{c}-0.2236 \\
(0.1791)\end{array}$ & $\begin{array}{l}-0.2543 \\
(0.2429)\end{array}$ \\
\hline FIFA Ranking Difference & & $\begin{array}{c}-0.0337 * * * \\
(0.0045)\end{array}$ & & $\begin{array}{c}-0.0195 * * * \\
(0.0029)\end{array}$ & & $\begin{array}{c}-0.0187 * * * \\
(0.0031)\end{array}$ \\
\hline Constant & $\begin{array}{c}0.5271 * * * \\
(0.0879)\end{array}$ & $\begin{array}{c}0.1675 \\
(0.1139)\end{array}$ & $\begin{array}{c}1.7421 * * * \\
(0.0655)\end{array}$ & $\begin{array}{c}1.3979 * * * \\
(0.0886)\end{array}$ & & \\
\hline Observations & 739 & 347 & 739 & 347 & 739 & 347 \\
\hline Joint Hypotheses All Rest & 0.25 & 0.66 & 1.10 & 0.31 & 3.70 & 0.89 \\
\hline Dummies $=0$ (p-value $)$ & $(0.9095)$ & $(0.6231)$ & $(0.3566)$ & $(0.8703)$ & $(0.4480)$ & $(0.9260)$ \\
\hline Adjusted R-squared & 0.119 & 0.166 & 0.093 & 0.090 & & \\
\hline Pseudo R-squared & & & & & 0.058 & 0.056 \\
\hline
\end{tabular}


Finally, we analyze if the difference in days of rest has an influence when the rest of the two teams between consecutive matches has been particularly brief or when it has been longer. A difference of one day could matter if opposing teams had respectively two and three days of rest, whereas the same difference could be irrelevant if the teams had six and seven days of rest.

To this aim, for each match in our sample we determine the minimum between the days of rest of Team A and Team B. Then, on the basis of this variable we split the sample in two subsamples: the first subsample includes the matches in which the minimum rest has been less or equal to 3 days and the second subsample comprises matches in which the minimum rest has been equal to 4 or longer. We expect an impact of differences in days of rest higher in the first case in which at least one of the two teams enjoyed a particularly brief period of rest.

We show the results of this exercise in Table 8. In the first two columns we study the effect on Goal Difference, while in columns (3) and (4) we analyze the impact on Points. In odd-numbered columns we report the regressions using the sample with brief periods of rest, while in even-numbered columns we use the sample of longer pauses.

However, we do not find any impact of difference in days of rest even on the sample with brief pauses. The effects are never statistically significant. It is worthwhile to note that by splitting the sample the variance of our explanatory variable is considerably reduced and this could affect the statistical significance of the effect.

Table 8. The Impact of Difference of Rest for Brief and Long Pauses

\begin{tabular}{|c|c|c|c|c|}
\hline & $\begin{array}{c}(1) \\
\text { Goal } \\
\text { Difference } \\
\text { Min Rest }<=3\end{array}$ & $\begin{array}{c}(2) \\
\text { Goal } \\
\text { Difference } \\
\text { Min Rest }>=4\end{array}$ & $\begin{array}{c}(3) \\
\text { Points } \\
\text { Min Rest }<=3\end{array}$ & $\begin{array}{c}(4) \\
\text { Points } \\
\text { Min Rest }>=4\end{array}$ \\
\hline Difference in Days of Rest & $\begin{array}{c}0.0303 \\
(0.0777)\end{array}$ & $\begin{array}{l}-0.1108 \\
(0.1020)\end{array}$ & $\begin{array}{c}0.0583 \\
(0.0548)\end{array}$ & $\begin{array}{l}-0.0554 \\
(0.0611)\end{array}$ \\
\hline Average Points Difference & $\begin{array}{l}0.2860 * \\
(0.1576)\end{array}$ & $\begin{array}{c}0.5393 * * * \\
(0.1339)\end{array}$ & $\begin{array}{c}0.1133 \\
(0.0925)\end{array}$ & $\begin{array}{c}0.2190 * * * \\
(0.0830)\end{array}$ \\
\hline \# Matches Difference & $\begin{array}{c}0.0131 * * \\
(0.0056)\end{array}$ & $\begin{array}{c}0.0148 * * * \\
(0.0034)\end{array}$ & $\begin{array}{c}0.0096 * * \\
(0.0045)\end{array}$ & $\begin{array}{c}0.0119 * * * \\
(0.0024)\end{array}$ \\
\hline Host Country Difference & $\begin{array}{c}0.2922 \\
(0.2178)\end{array}$ & $\begin{array}{c}0.8888 * * * \\
(0.2024)\end{array}$ & $\begin{array}{c}0.1657 \\
(0.1717)\end{array}$ & $\begin{array}{c}0.5889 * * * \\
(0.1437)\end{array}$ \\
\hline Extra Time Difference & $\begin{array}{l}-0.1479 \\
(0.3187)\end{array}$ & $\begin{array}{l}-0.2883 \\
(0.2692)\end{array}$ & $\begin{array}{l}-0.2120 \\
(0.2505)\end{array}$ & $\begin{array}{l}-0.1908 \\
(0.2431)\end{array}$ \\
\hline Constant & $\begin{array}{c}0.9344 * * * \\
(0.1121)\end{array}$ & $\begin{array}{c}0.2658 * * * \\
(0.0758)\end{array}$ & $\begin{array}{c}2.0417 * * * \\
(0.0830)\end{array}$ & $\begin{array}{c}1.5705 * * * \\
(0.0582)\end{array}$ \\
\hline $\begin{array}{l}\text { Observations } \\
\text { Adjusted R-squared }\end{array}$ & $\begin{array}{c}249 \\
0.032\end{array}$ & $\begin{array}{c}490 \\
0.171\end{array}$ & $\begin{array}{c}249 \\
0.022\end{array}$ & $\begin{array}{c}490 \\
0.130\end{array}$ \\
\hline
\end{tabular}




\section{Concluding Remarks}

We have investigated the role of fatigue in soccer. Although neglected in the economics of sport literature, this issue is relevant for the productivity of players and the optimal scheduling of national and international tournaments, because whether fatigue has any impact, the "productivity" of players could be seriously undermined and the balance between teams could be altered.

We have used data from all the matches of the final tournaments of World Cup and the European Championship. In these tournaments, matches are staggered to increase TV audience and, as a consequence, teams are often assigned different spells of rest between consecutive matches: we are therefore able to investigate the impact of differences in days of rest on team performance.

Using different estimation methods and controlling for several measures of teams' abilities, we do not find any significant effect of rest on team performance (neither in terms of goal difference nor on points gained).

Our results imply that, notwithstanding several concerns of coaches, players and supporters, the current organization of international championships as regards the scheduling of the matches is adequate and players' productivity and the competitive balance do not seem to be altered.

In addition, these findings have key implications for the organization of national League matches interspersed with matches of international competitions, such as Champions League and Europa League in European countries. If our results are also valid at level of club teams, teams playing on average two matches at week (one for the national League and the other for some European Cups) - should not be less competitive with respect to other teams involved only in national League, playing only once a week. Research currently in progress is aimed to verify this aspect.

\section{References}

Ashman, T., Bowman, and Lambrinos, A. (2010), "The Role of Fatigue in NBA Wagering Markets: The Surprising "Home Disadvantage Situation", Journal of Sports Economics 11(6) 602-613.

Bangsbo, J. (1994), "The physiology of soccer - with special reference to intense intermittent exercise", Acta Physiologica Scandinavica, 151 (suppl. 619).

Carmichael F., Thomas D. (2005), "Home-field effect and team performance", Journal of Sports Economics, 6(3), pp. 264-281.

Courneya, K.S. and Carron, A.V. (1992), "The Home Advantage in Sport Competitions: a Literature Review," Journal of Sport and Exercise Psychology, 14, pp. 13-27.

Entine, O. A., and Small, D. S. (2008). The role of rest in the NBA home-court advantage. Journal of Quantitative Analysis in Sports, 4, pp. 1-9.

Fried, H. and Simmons, R., (2011), "Introduction", Journal of Productivity Analysis, 35:1-3.

Gandar, J.M., Zuber, R. A., and Lamb, R. (2001). The home field advantage revisited: A search for the bias in other sports betting markets. Journal of Economics and Business, 53, pp. 439-453.

Karlis D. and I. Ntzoufras, (2003), "Analysis of sports data by using bivariate Poisson models", The Statistician, 52(3), pp. 381-393.

Koning R.H. (2003), "An econometric evaluation of the firing of a coach on team performance", Applied Economics, 35, pp. 555-564. 
Mohr, M., Krustrup, P., \& Bangsbo, J. (2003). "Match performance of high-standard soccer players with special reference to development of fatigue", Journal of Sports Sciences, 21, 439-449.

Monks, J. and Husch, J., (2009), "The Impact of Seeding, Home Continent, and Hosting on FIFA World Cup Results", Journal of Sports Economics, 10: 391

Nevill, A.M. and Holder, R.L. (1999), "Home Advantage in Sport: An Overview of Studies on the Advantage of Playing at Home," Sports Med, 4, pp. 221-236.

Nichols, M., (2012), "The Impact of Visiting Team Travel on Game Outcome and Biases in NFL Betting Markets", Journal of Sports Economics, forthcoming, pp. 1-19.

Oberhofer, H., Philippovich, T., Winner, H. (2010), "Distance Matters in Away Games: Evidence from German Football League", Journal of Economic Psychology, 31, pp. 200-211.

Pojskić, H., Šeparovic, V. and Užicanin, E. (2011), "Modelling home advantage in basketball”, Acta Kinesiologica, 5 1, pp. 25-30.

Reilly, T. (1997) "Energetics of high-intensity exercise (soccer) with particular reference to fatigue", Journal of Sports Sciences 15, 257-263.

Scoppa, V. (2008), "Are Subjective Evaluations Biased by Social Factors or Connections? An Econometric Analysis of Soccer Referee Decisions", Empirical Economics, 1, pp. 123-140. 